\title{
INFÂNCIA PORTUGUESA ENTRE A PENUMBRA DA INFRAÇÃO E A LUZ DA PROTEÇÃO (SÉC. XIX-XX)
}

\author{
PORTUGUESE CHILDHOOD BETWEEN THE PENUMBRA OF THE INFRACTION AND THE LIGHT OF \\ PROTECTION (19TH AND 2OTH CENTURIES)
}
INFANCIA PORTUGUESA ENTRE LA PENUMBRA DE LA INFRACIÓN Y A LA LUZ DE LA PROTECCIÓN (SIGLOS XIX-XX)

\author{
Ernesto Candeias Martins \\ Doutor em ciências da educação pela Univ. Illes Balears Palma de Mallorca Espanha. Docente no Instituto \\ Politécnico de Castelo Branco/Escola Superior de Educação. \\ E-mail: ernesto@ipcb.pt. \\ Orcid: https://orcid.org/0000-0003-4841-1215
}

\begin{abstract}
RESUMO
O nosso estudo de natureza sócio-histórico aborda a infância marginalizada, vadia, infratora e/ou delinquente portuguesa, no período do Séc. XIX e inícios do Séc. XX, a qual vivia numa subcultura à margem da sociedade, considerada perigosa para a coesão social. Norteamos-nos neste fenómeno social daquela infância (fenomenologia), por uma argumentação hermenêutica. O corpus documental recorre a fontes primárias da época e análises de estudos posteriores, que dão ênfase às relações entre aquela infância e o poder político-ideológico, reformas sociais para normalizar aquela infância, medidas assistenciais e de proteção para serem cidadãos úteis. Guiamo-nos pelos seguintes objetivos: compreender as políticas sociais, as medidas estabelecidas na governação da infância vadia, errante, infratora ou delinquente; analisar as relações de poder sobre esse tipo de infância, com o intuito de suprir o estado de marginalização e desviação social, em que estava imersa; interpretar essa infância recorrendo aos discursos políticoideológicos, científicos e filantrópicos, cujo objeto de análise era esse problema social da criança/infância à margem da sociedade. A estrutura do texto assenta em 4 pontos: o surgimento das medidas de reforma social à proteção da infância (séc. XVIII) com a pretensão de assistir, acolher, regenerar, educar e reinserir; oscilação da intervenção por parte do Estado na 'governação e profilaxia' e os discursos científicos e filantropos da época oitocentos; abordagem às diretrizes de correção, de organização e medidas reeducativas com essa 'Outra Infância'; e a via infame da marginalização à proteção, no início de novecentos, ao menor infrator ou delinquente.
\end{abstract}

Palavras-Chave: Criança vadia. Infância infratora. Delinquência infantil. Proteção infantojuvenil. Instituições de menores.

\footnotetext{
ABSTRACT

Our socio-historical study addresses marginalized childhood, slut, offender and/or Portuguese delinquent, in the period of the 19th century. 19th century and early 19th century. xx, which lived in a subculture on the margins of society, considered dangerous for social cohesion. We are guided by this social phenomenon of that childhood (phenomenology), by an argument action of hermeneutics. The documentary corpus uses primary sources of the time and analyses of later studies, which emphasize the relations between that childhood and the political-ideological power, social reforms to normalize that childhood, to assistance and protection measures to be useful citizens. We are guided by the following objectives: to understand social policies, the measures established in the governance of children who are slutty, wandering, delinquent or delinquent; to analyze the power relations over this type of childhood, in order to supply the state of marginalization and social deviation, in which they were immersed; interpreting this childhood using political-ideological, scientific and philanthropic discourses, whose object of analysis was this social problem of the child/childhood outside society. The structure of the text is based on 4 points: the
} 
emergence of social reform measures for the protection of children (19th century). XVIII) with the intention of assisting, welcoming, regenerating, educating and reinserting; oscillation of state intervention in 'governance and prophylaxis' and the scientific and philanthropic discourses of the eight hundred era; and the infamous route from marginalization to protection, at the beginning of nine hundred, to them minor offender or offender.

Keywords: Child slut. Childhood offender. Child delinquency. Child and adolescent protection. Institutions of minors.

\section{RESUMEN}

Nuestro estudio socio-histórico aborda la infancia marginada, abandonada, infractora y/o delincuente portuguesa, en el período del Siglo XIX y principios del XIX, que vivía en una subcultura al margen de la sociedad, la cual consideraba peligrosa para la cohesión social. Nos guiamos por este fenómeno social de la infancia (fenomenología), en base a una argumentación hermenéutica. El corpus documental utiliza fuentes primarias de la época y análisis de estudios posteriores, que enfatizan las relaciones entre esa infancia y el poder político-ideológico, las reformas sociales de normalización de esa infancia, las medidas de asistencia y protección para ser ciudadanos útiles. Establecemos los siguientes objetivos: comprender las políticas sociales, las medidas establecidas en la gobernanza de los niños que son zorras, errantes, delincuentes o delincuentes; analizar las relaciones de poder sobre este tipo de infancia, con el fin de abastecer el estado de marginación y desviación social, en el que estaban inmersos; interpretando esta infancia utilizando discursos político-ideológicos, científicos y filantrópicos, cuyo objeto de análisis fue este problema social del niño/infancia fuera de la sociedad. La estructura del texto se basa en 4 puntos: el surgimiento de medidas de reforma social para la protección de los niños (siglo XVIII) con la intención de asistir, acoger, regenerar, educar y reinsertar; oscilación de la intervención estatal en la "gobernanza y profilaxis" y los discursos científicos y filantrópicos de la era ochocientas; y la infame ruta de la marginación a la protección, al comienzo de los novecientos, al menor delincuente u delincuente.

Palabras clave: Niño desvalido. infancia infractora. Delincuencia infantil. Protección de la infancia y adolescencia. Instituciones de menores.

\section{INTRODUÇÃO}

É sabido que a Modernidade produziu a imagem da criança e da sua infância no seio dos foros político-ideológicos, científicos (médico-social, jurídico-legal, assistencial, pedagógico e/ou psicológico) e do social (debate público). De facto, as relações com a infância foram feitas como uma diferenciação e naturalização, que implicou uma mudança conceitual, que fez surgir conceções e representações sociais próprias. Essa modernização instituiu um processo civilizador do mundo adulto e da criança, na pretensão de ser criança civilizada e normalizada, compreendida como produção sociocultural, com novas relações de autoridade e nas formas de comportamento (KING, 2007). Ou seja, distinguia-se o tempo de infância (etapa natural da vida) do tempo social da infância (categorias, divisões). A tríade 'família - escola - infância' desencadeou a emergência do sentimento para com ela, de tal forma que, no séc. XIX, a vida social do adulto misturava-se com a da criança e esta em torno à família e à educação/instrução. Vários indicadores estruturaram o modelo ideal de infância, em base da ótica da 
burguesia (liberal) e da lógica da ideologia dominante, dando atenção às crianças não enquadradas no seu modelo padrão (normalização, escolarização, socialização) e, em especial, as consideradas conflitivas, perigosas, delinquentes e/ou em desviação social, assim como, às suas famílias (AMADO, 1986). O cenário do desvio, da devassidão e da marginalização social inseriu-se num movimento europeu, em que as políticas de proteção à infância foram uma resposta para conter a exclusão das gerações futuras. Assim, a proteção e o controlo social daquela infância constituiu uma forma de proteger a sociedade das suas ameaças sociais latentes, da necessidade de um 'higienismo social' (assistencial, educativo), em que a intervenção do Estado impedia esse 'contágio' e, para tal, surgem serviços e instituições (asilares) de índole filantrópico (CARRILLO; ASTARITA; VOGEL; PETIT et al., 1998).

$\mathrm{Na}$ verdade, passou-se do interesse e da visibilidade pela infância para a emergência reformista da sua assistência e proteção, intervindo nas questões do seu desenvolvimento, situação da família e influência do meio envolvente, principalmente as condições imorais, degradantes ou marginalização. Neste interface, de várias situações e condições de conflito, aparece um leque de nomenclaturas e aceções sobre a criança, correspondentes ao seu segmento social, que originou que a sua infância fosse uma infância diferenciada do projeto liberal/burgês e dos seus discursos, por exemplo, as designações: criança exposta, pobre e mendiga; criança abandonada e/ou desamparada; criança vadia/errante ou desvalida; criança infratora e/ou delinquente; criança marginal; etc. Muitas dessas designações integravam a criança/infância 'em perigo moral' (TOMÉ, 2010), mas qualquer uma delas tem uma definição e significado (etimologia) próprio nos dicionários de oitocentos e novecentos, nos discursos médico-higienistas, jurídico-sociais e (socio)pedagógicas e psicológicos. De facto, a situação dessas infâncias, nas suas interações com a errância e comportamentos delitivos ou ilegais, evidenciava, à luz da opinião pública e da imprensa, os diferentes cenários em que vivia (familiar, social, institucional), sabendo que o seu destino era traçado pelos códigos penais (séc. XIX) e pelas medidas assistenciais ou correcionais da época até à publicação da LPI -Lei de Proteção à Infância -início do direito tutelar de menores (PORTUGAL, 1911). Pois bem, todas aquelas nomenclaturas de criança/infância, na nossa conceptualziação, aglutinamse no chapéu de 'Outra Infância', ao distingui-la, de forma diferenciada, da dita normal, devido às suas situações familiares, fatores endógenos e exógenos que a afetava. Ou 
seja, essa 'Outra Infância' vivia uma anormalização à margem e/ou na fronteira dos ditâmes da sociedade liberal. Ela constituía um problema social na sociedade e, assim, os reformadores sociais, ajudados pelos contributos de várias ciências médicas, jurídicas e (pisco)pedagógicas, promoveram sistemas e medidas de proteção, assistência e (re)educação (CASTRO, 1913; VASCONCELOS, 1913).

O nosso estudo de natureza sócio-histórico (descritiva, documental) aborda a infância marginalizada, vadia, infratora e/ou delinquente portuguesa, no período do Séc. XIX e inícios do Séc. XX, a qual vivia numa subcultura, considerada perigosa para a coesão social. Norteamos-nos na nossa análise por uma argumentação hermenêutica. O corpus documental tem por base fontes primárias da época e análises de estudos posteriores (fontes secundárias), que deram ênfase às relações entre aquela 'Outra Infância' e o poder político-ideológico e/ou as reformas sociais para as normalizar, com as medidas assistenciais e de proteção para a regenerar, educar e reinserir como cidadãos úteis (FERREIRA, 2000). Deste modo, elencamos os seguintes objetivos: compreender as políticas sociais, as medidas (assistenciais) estabelecidas na governação da infância vadia, errante, infratora e/ou delinquente, através da normalização imposta na época; analisar as relações de poder sobre esse tipo de infância, com o intuito de suprir o estado de marginalização e desviação social, em que estava imersa; interpretar essa infância recorrendo aos discursos político-ideológicos, científicos e filantrópicos, cujo objeto de análise era esse problema social da criança/infância à margem da sociedade. Ora bem, a estrtutura do texto assenta em 4 pontos: o surgimento das medidas de reforma social à proteção da infância no séc. XIX com a pretensão de assistir, acolher, regenerar, educar e reinserir; a oscilação pendular da intervenção, por parte do Estado, na 'governação e profilaxia', tendo em conta os discursos científicos e filantropos de oitocentos; abordagem às diretrizes de correção, organização e medidas reeducativas com essa 'Outra Infância'; a via infame do menor infrator/delinquente na marginalização.

\section{A débil fronteira em oitocentosde quem estende a mão para pedir à mão que rouba $e$ infringe: corrigir e regenerar}

Neste ponto pretendemos dar a conhecer a existência das crianças desvalidas e a reação do Estado e reformistas na promoção de medidas assistenciais e de proteção, com 
o intuito de a corrigir e regenerar. Uma dessas medidas foi a fundação, em 1834 da organização de dimensão nacional, a Sociedade das Casas de Asilo da Infância Desvalida, destinada a acolher crianças de ambos sexos com a idade dos 2 aos 7 anos (rapazes) ou até aos 9 anos (raparigas). Essas instituições asilares intentavam resolver o problema da infância, que passava o dia sozinhas a vaguear/mendigar pelas ruas/praças citadinas, enquanto os pais ou um deles trabalhava. Devido a essa chusma de crianças em perigo moral e desvalida as autoridades intervieram socialmente, criando-se instituições (asilos de mendicidade, asilos-escola, albergues, hospícios), que eram o ponto de confluência da realidade social e das conceções das elites (liberal, burguesa), no entrelaço do mental e do concreto que respondia o Antigo Regime (SANTOS, 2002). O primeiro asilo surge em Lisboa, em 1836, seguindo-se o do Porto, para essa infância (para os recém-nascidos havia as Rodas de expostos nas misericórdias ou estabelecimentos religiosos) (FONSECA, 1913) e no ano seguinte surgem as comissões de beneficência em cada capital de distrito e asilos albergues. O Decreto Régio (19/09/1836) de Passos Manuel uniformizou os serviços de expostos e cimentou as bases organizacionais do acolhimento, em parte, devido aos índices elevados de mortalidade infantil, abandono e orfandade.

Historicamente a evolução do conceito e tratamento da pobreza, mendicidade e vadiagem, provinha de anteriores séculos, passando pela fase da sacralização na modernidade (caridade), racionalização dos pobres no reformismo social (beneficência com reclusão) e da individualização do pobre no liberalismo burguês (assistência social pelos municípios). Muitos programas de intervenção tiveram pouca eficácia na prática (CATROGA, 1977). Por exemplo, já, em 1780, Pina Manique criou a Casa Pia de Lisboa (a do Porto foi em 1789) para encerrar e cuidar da infância mendiga, vadia ou desvalida. Porém, o impulso em toda a Europa para conceptualizar a infância, como um estado de desenvolvimento próprio e com as necessidades de cuidado especial, fez criar em novecentos um quadro jurídico-social, com medidas contra a mendicidade, a errância e a delinquência, com o controlo policial, as disposições dos códigos penais e os tribunais, para reprimir e corrigir essa infância. Em Portugal a legislação foi muito repressiva e, aquando da ascenção dos liberais ao poder, a ação jurídico-legal promoveu a criação de estabelecimentos para muitos desses coletivos desvalidos ou marginalizados (XAVIER, 2017). Naquela época cabia às câmaras municipais promover e financiar as reparações das cadeias, onde se encerravam muitos menores, mas com o advento do liberalismo e uma 
nova ordem administrativa, cabendo aos administradores dos concelhos e aos governadores civis assumiram essa responsabilidade prisional (Portaria de 30/06/1838 incumbia os governos civis da organização e sustento dos presos pobres nas localidades onde não existissem Misericórdias, secundado pelo Código Administrativo de 1836).

Com o Código Penal de 1852 veio-se punir a vagabundagem/vadiagem e a mendicidade, com prisão correcional, mas esse comportamento errante era extensivo à infância, o que inquietava as autoridades, filantropos e opinião pública, para esse perigo social. Alertavam, em especial, para a situação da infância (desvalida), que era explorada por adultos ou familiares, sem escrúpulos, ou então, viviam entregues a si próprias pelas ruas citadinas ou fazendo alguns fretes. De facto, aquela infância apresentava uma imagem negativa para os Códigos Penais de oitocentos, pois não tinham domicílio certo, meios de subsistência, nem prática de um ofício ou exercício de profissão. Para ela havia a detenção e a prisão correcional, até 6 meses (dispositivos judiciais), ficando à disposição do Estado, para lhe dar trabalho e efetuar a sua regeneração (CÓDIGO PENAL

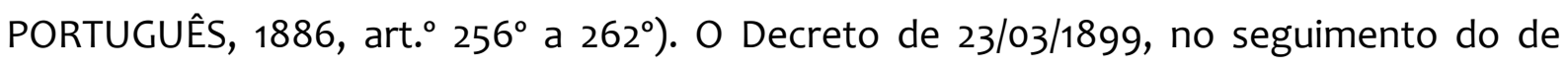
1886, regula as disposições, a admissão e o destino dos vadios, infratores e mendigos detidos, incluindo os menores. Em julgado os delegados do Procurador Régio enviavam uma cópia ao Governador Civil, onde se propunha o destino do menor vadio detido (SANTOS, 1999). O percurso deste menor ia desde a detenção pelas forças policiais, à justiça e condenado em julgado, posto à disposição do Governo para ser regenerado, ou então, davam-lhe trabalho em obras públicas, ou internava-o em casas de correção [1], asilos-escola, ou deportando-o para as províncias ultramarinas. A maior parte destas instituições não possuíam condições adequadas de internação (FERREIRA, 2000).

A vadiagem, vagabundagem e delinquência eram situações endémicas na sociedade, normalmente visadas pela legislação jurídico-legal no período da Monarquia até à $1 .^{\text {a }}$ República, reprimindo aquelas situações sociais e de conflito, na segunda metade do séc. XIX. De facto, os flagelos sociais nas famílias e das respetivas crianças exigiam

1No séc. XIX as casas de correção foram entendidas de diferentes maneiras, já que provinham de séculos anteriores, aplicadas a hospícios e casas de beneficência, dependências onde se recluiam pobres, 'viciosos', errantes ou vadios com conduta ireegular. Legislativamente, no ãmbito penitenciário, foi a designação que recebeu as cárceres femininas no séc. XX, em substituição de galera. A partir de meados de oitocentos as casas de correção aludiam tanto a prisões, cárceres como presidios de reclusão, com tratamento ressocializador para cidadania, na linha correcionalista na época, se bem que a sua tradição seja francesa e americana. No caso português adotou-se por 'Casa de Detenção e Correção (a de Lisboa de 1871, a do Porto em 1902) que era uma instituição de reclusão de jovens com comporatmentos delinquentes a quems e aplicava sistema redducativo socialziador. 
respostas sociais e assistenciais do poder político, sempre de difícil resolução prática, de tal forma, que em novecentos mantinham-se muitos vadios típicos nas cidades, refratários ao trabalho, jovens profissionalizados em esmolar, pedinchar, estafar e roubar (indigência e ociosidade) ou impelidos para uma vadiagem acidental ou ocasional, a par com o aparecimento de outro tipo de vadio errante e delinquente (isolado ou em grupo), resultante do processo de industrialização e urbanização. Todos esses males sociais preocupou o Estado (políticos), os filantropos, a maçonaria, a imprensa, escritores e cientistas (médicos, juristas, psiquiatras criminólogos, higienistas, pedagogos), pois essa imagem contribuía para uma tomada de consciência desses estados de miséria/pobreza nas classes populares e/ou operárias. A repressão, regeneração e correção institucional pelo trabalho foi o dispositivo mais comum das autoridades (leis contra a mendicidade, trabalho infantil), recorrendo à beneficência privada, incentivada em termos socioculturais por uma vertente moral e cívica e pela inserção social/laboral. Daí que as atividades nas instituições asilares e em outras de beneficência passassem pela aprendizagem de um oficio, educação elementar e regeneração moral, para além da disciplina do regulamento. Em geral, a maioria dos vadios detidos eram essencialmente do sexo masculino, já que a mulher era socialmente mais protegida ou enveredava por outras formas de marginalidade (prostituição) (VASCONCELOS, 1913). De facto, o vadio masculino engendrava mais expetativas sociais que a mulher e, porque no Antigo Regime não se esperava que a mulher trabalhasse em termos sociais/mentais, sendo normal as tarefas domésticas/agrícolas ou, então, em oficinas/fábricas.

Por outro lado, era normal haver uma morosidade no sistema judicial (burocracia e falta de recursos) que obrigava o menor a permanecer em regime de detenção ou prisão preventiva por largos meses, mesmo estando já à disposição o Governo a aguardar o seu destino (PORTUGAL, 1880-1962). As prisões em Lisboa (Aljube, Limoeiro) e no Porto e as casas de correção eram palcos de atores da miséria, da vadiagem e do crime, sendo fáceis de identificar pelas suas caraterísticas físicas e linguísticas. Quando o menor entrava pela primeira vez nas casas de correção (semelhantes a prisões na época) verificava que estas instituições funcionavam mais de "[...] aprendizagem de vícios que de regeneração", ao haver mistura de idades e de tipos de crimes (SANTOS, 1996, p. 194). Aqueles menores desafortunados apresentavam uma caraterização específica da sua proveniência, com traços físicos e psicológicos, alcunhas e linguagem marginal (calão). A expressividade 
dessa infância está bem evidente, em muitos Arquivos Fotográficos camarários (Lisboa, Porto), arquivos particulares de fotógrafos, na revista Ilustração Portuguesa, Fototeca do Palácio Foz, documentação de asilos, Instituto Português de Arquivos, coleções iconográficas, etc., sendo ainda, interessante as notícias da imprensa e fotojornalismo de menores no seu 'habitat' (rua): de rostos magros, pálidos e enfezados; com mazelas ou chagas; esfarrapados ou com poucas vestes encardidas; descalços, calçado esburacado ou inexistente; sujos e malcheirosos; alguns com boina ou chapéu; etc. Esta 'Outra Infância' constituía um espetro de doenças, que se vincam nos seus traços físicos de miséria e doenças sociais e mentais, tal como nos pais, e é vê-los sozinhos, em bandos ou junto a cegos, andrajosos e aleijados, reforçando as suas lamúrias, pedinchando e puxando pelas vestes dos transeuntes para obrigá-los a dar uma esmola. Havia por parte das pessoas, um sentimento de repulsa, de caridade e piedade (PINTO, 1999).

A detenção do menor provocava nele uma tendência à reincidência, como ação lógica, já que ao sair do 'encerramento' havia mais probabilidades de aí voltar, do que antes de entrar nele. Estatisticamente havia uma pequena percentagem de reincidentes, entre os 30\% a 40 \% (LOPES, 1897). Estas situações fizeram que as autoridades analisassem estas situações (correspondência oficial entre procurador régio e o Governador Civil, relatórios anuais dos movimentos de menores nas instituições, processos individuais), considerando que essa permanência era prejudicial para os menores sem cadastro junto aos mais viciados ou reincidentes (MARTINS, 1997). Também a incorporação ao serviço militar, gerava vadios, mendigos e vagabundos, já que muitos menores fugiam ao recrutamento e enveredavam pela errância ou, então, aqueles que faziam a tropa, ao sair dela como não tinham profissão definida dedicavam-se à mendicidade e a fretes. (CARRILLO; ASTARITA; VOGEL; PETIT et al, 1998). É evidente que a causa de abandono e vadiagem infantojuvenil, muitas vezes, se associava às flutuações de procura de emprego das suas famílias, criando nos centros urbanos um submundo de desempregados, vagabundos, mendigos, indigentes e criminosos. O subemprego e o desemprego, a deslocação da imigração do campo para as grandes cidades, nos dois últimos séculos, incentivavam ao aparecimento de jovens em situação de desviação e conflito social, de exclusão, marginalização e delinquência. A etapa entre os 10 e os 14 anos era aquela em que a família intentava empregar o menor, apesar de em 1891 se ter regulado a sua admissão ao mundo laboral (12 anos em estabelecimentos industriais e construção civil). 


\section{Visão pendular de intervenção: da 'governação e profilaxia' aos discursos do Estado}

Ao longo dos séculos XIX e XX o problema da marginalização e desviação social da infância alcançou uma grande visibilidade (exposição pública), na sociedade. O Estado recorreu a um conjunto de conheciemntos científicos em emergência (direito e criminologia, medicina e psiquiatria, pedologia e psicologia) para encontrar respostas a esses problemas decorrentes do processo regulador da sua política-ideológica, na construção de um cidadão novo, disciplinado e socializado à medida dos padrões impostos. De facto, a questão social da 'Outra Infância' constituía uma ameaça geracional que colocava em risco a construção moderna e a civilidade do Estado-Nação. Igualmente, nos inícios de novecentos, o regime republicano colocou na sua agenda a 'criança e educação' como elemento fulcral no processo de regeneração e progresso da sociedade portuguesa. As tentativas de resolução dos problemas dessas infâncias com o objetivo de construir, pela educação, individuos úteis, produtivos e dóceis, cidadãos conformes com as normas sociais (FOUCAULT, 2006), tinha, também como propósito central a família, no papel de criar condições 'normalidade' ao desenvolvimento da criança e da sua infância, caso contrário seria substituída pelo Estado, que exerceria a sua ação tutelar pelos seus dispositivos (serviços, instituições). Os processos de proteção, reeducação e reinserção dos menores transformaram-se numa causa pública e de intervenção preventiva e social. No âmbito da assistência pública (Lei de Assistência de 25/05/1911) e da proteção à infância (PORTUGAL, 1911), abrangia-se diferentes aspetos, como a proteção à mãe, a assistência materno-infantil, a lactância, etc. (MAGALHÃES, 1912). Desta forma o Estado era zeloso pela proteção da criança, desde a sua nascença ao seu desenvolvimento e, ainda naquelas situações em perigo moral ou marginalização social, passíveis de anormalidade. Claro que um dos aspetos para evitar essa anormalidade era retirá-la ou afastá-la dos ambientes nocivos e promíscuos onde vivia e, conseguir transformá-la pelos valores sociais e educação protetora. Valorizava-se, assim, com a ação profilática do Estado a educação e o direito tutelar, como elementos preventivos (LIMA, 1913).

Por conseguinte, há uma grande dificuldade em analisar as crianças infratoras e desvalidas, em oitocentos e inícios de novecentos, por falta de estatísticas e de estudos, de testemunhos de vida institucional de internação. A socialização do vadio passava por 
estadias nos meios marginais (rua), incluindo as prisões e/ou casas de correção para menores. É verdade que o triunfo progressivo do liberalismo e a pressão demográfica, trouxe consigo um aumento de pobres, mendigos e vadios, ou seja, vidas analfabetas, errantes, marginais e criminosos (GOMES, 1892). Apesar das medidas legislativas, da punição nos códigos penais e da regulação da assistência nos códigos administrativos (municípios) para intentarem atenuar essas situações sociais verificava-se um certo aumento que, em geral, levava à internação e/ou reclusão, ao degredo, desterro, etc. (SANTOS, 2002). Se no século da filantropia se redesenhou uma nova conceção nas relações entre as classes altas e elitistas e os pobres e as classes populares, encaradas como participantes no movimento do progresso técnico, industrial e educativo, na base do princípio da utilidade social, fez surgir uma caridade organizada, com preocupações humanitárias e de beneficência. A transformação dessa infância em 'valor social' de cidadania na 1. ${ }^{a}$ Republica (1910-26) fez-se pela ação das Tutorias da Infância e Refúgios anexos (lugares de observação, despistagem e reeducação), pelos serviços jurisdicionais de menores, serviços preventivos e assistenciais, ou ainda, pelos estabelecimentos especiais (1911-19 -escolas de reforma; 1919-62 -reformatórios e colónias agricolas corecionais), onde se conjugava a educação e o trabalho (aprender um ofício). Este sentido de ordem protecionista, imprimido pelo Estado, permitiu o desocultamento de vários tipos de infância, desde a pobre/mendiga ou órfã, a desvalida/vadia, em perigo moral (em risco), infratora ou delinquente, classificada em condição de marginal social, por não se integra no padrão social e ser um perigo para a coesão da sociedade.

Ao nível da intervenção socioeducativa, uma das diferenças de trato com o menor detido e/ou internado era a sua plasticidade em ser (re)educável, com possibilidades de endireitar as possiveis inclinações ou desvios sociais. Assim, os reformadores sociais favoreceram o modelo de tratamento correcional e/ou (re)educativo, na base de medidas médico-pedagógicas, uma regeneração moral e uma educação pelo trabalho (ROTHMAN, 1971). As soluções ao problema da infância abandonada, infratora e delinquente foi mais pedagógica que penalizadora, fomentando-se a educação e reinserção social nas instituições asilares e correcionais de oitocentos e, posteriormente, já em novecentos nas escolas de reforma e reformatórios de novecentos, tendo em conta as tipologias próprias (exames antropométricos), a separação por seções (preparatória, técnica ou profissional e disciplinar), ou divisões (impúberes, púberes e pós-puberes) nessas instituições. 
Na verdade, a governação profilática imposta pelos discursos do Estado procurava a educação e a reinserçãos social dessa 'Outra Infância', com formulas de correção rígidas, que assentavam numa ação de prevenção primária (promoção, intervenção social nas famílais), numa ação secundária (atenção e cuidado na base legal e policial) e numa ação de proteção sobre os menores infratores e delinquentes pela forma reativa. Esta última começou a difundir-se nos inícios de novecentos com as tutorias de Infância para a infância em perigo moral (GENOVÊS, 1990). Lembramos que o positivismo discutia a existência da 'herança criminal' como simples prédisposição do menor (teoria de Lombroso), contraposta com outros partidários criminalistas que incluiam os fatores exógenos ou ambientais no delinquente (GOMES, 1892; SANTOS, 1996).

\section{Diretrizes de correção, de organização e medidas reeducativas}

Historicamente, as reformas sociais, quer nos sistemas prisionais (modelo pensilvanico e de Auburn), quer na proteção à infância e governação das instituições de enceramento, que teve nos EUA o seu gérme de discussão e seguimento por muitos países europeus. Procurava-se a eficácia e a equidade da justiça, a eficácia e a proporcionalidade das penas e o impedimento dos excessos que se produziam nos estabelecimentos penitenciários (e prisões, cárceres), casas de correção e asilos, procurando a separação de presos /internados e melhoria das suas condições materiais e higiénicas. Desde o séc. XVIII assistiu-se a uma viragem para uma humanização das penas, substituindo a aplicação no corpo (castigos) pela regeneração da alma, eliminando progressivamente a tortura e a privação de liberdade como pena. Deu-se pois, a entrada da racionalidade no mundo penal (apenas ao nível teórico) e a concetualziação dos estabelecimentos de encerramento prisional e correcional. Assim os edificios, a organização interna, as técnicas e modelos correcionais e a disciplina foram-se reformando e adaptando-se aos novos preceitos do séc. XIX e depois no séc. XX. Podemos dizer que essas reformas sociais assentaram em 4 diretrizes:

(a)-Correção e/ou regeneração moral do (menor) delinquente, pelo internamento, medida útil para transformar a sua conduta pela disciplina da mente e corpo. A correção inisistia na parte espiritual do menor, mediante a educação (instrução, ensino moral e religioso) e no corpo pela disciplina pelo trabalho, ginástica militar, higiene (influência 
médico-higienista), nutrição, atividades, etc. Tudo isto implicava um controlo no tempo de reclusão, regulamentado pela organização de horários rotinários e momentos de ócio.

(b)-Organização interna (classificação e seções dos internados), segundo o sexo, idade, tipologia do crime ou infração cometida, experiencia delitiva e situação judicional (separava os que aguardavam julgamento dos sentenciados), advogando os "reformistas sociais pelo isolamento" (grau de isolamento absoluto ou moderado) e, na medida do possível o “contágio social” (ROTHMAN, 1971, p. 80-81).

(c)-Metodologia correcional, na base do trabalho (elemento terapêutico contra a imoralidade, paixões e impulsos), para evitar a ociosidade (causa dos males da errância e delinquência) e estabelecer a normalização dos costumes, proveniente dos discursos de filantropos e políticos, ao desejarem a sua conversão em trabalhadores submissos e cidadãos úteis à sociedade da época.

(d)-Distribuição do espaços de internação, apesar da maioria das instituições de encerramento estarem em edifícios antigos (adaptação das instituições religiosas ou palácios), havia intenção de separar as camaratas ou celas, criar níveis/seções nas oficinas, no refeitório e espaços de atividades (PERROT, 1980). Toda a vida de internação estava submetida a um controlo disciplinar e uma vigilância de pessoal, sem qualificação para este minister, pois tratavam os internados como 'gado' humano (OLIVEIRA, 1923).

No Antigo Regime as instituições de beneficência funcionavam como 'correcionais' para a infância desvalida, mas essas instituições necessitavam de se reequacionar, uma vez que a meados do séc. XIX se criou outras instituições (casas de correção, colónias agrícolas) para a infância marginalizada e delinquente. As iniciativas privadas de caráter filantrópico completavam o cenário institucional dos atores sociais nas políticas sociais, destacando-se também o voluntariado social ('maternidade social' das mulheres burguesas e liberais nessa ideia social) (BORRAS LLOP, 1996, p. 477), que foi um elemento imprescindível na melhoria assistencial e educativa à infância (desvalida), uma vez que o Estado era incapaz de assumir economicamente esse gasto público da beneficência com a infância (ROCHA; FERREIRA, 1994). As instituições asilares e as de acolhimento, facultavam uma assistência educativa que condicionava o estado físico e psicológico dos internados, visando transformá-los em cidadãos. Essas modificações eram mais na aparência de cumprimento de normas (farda, corte de cabelo, regras de higiene, número de identificação, etc.) que de reeducação das tendências e vícios que neles persistiam. 
Isto é, continuavam a ser uma categoria social distinta dentro das infâncias, havendo uma parte ansiosa de se regenerar e (re)educar (proteção do Estado por internamento) e outra com a tendência de ir para a 'rua', para se governar e continuar a estar em desviação social (os ditos incorrigíveis).

Era óbvio que o perfil de condutas desviantes e marginalizadas dessas crianças, neste período histórico, manifestava-se pela mendicidade, vadiagem, prática de jogos ilícitos, o furto/roubo, prostituição, etc. O furto constituía a maior percentagem entre os delitos cometidos, bem expressos nas estatísticas judiciais (Anuários Estatísticos do Reino de Portugal) que nas últimas décadas de oitocentos apontavam para os seguintes dados de detenção (GOMES, 1892; LOPES, 1897): em 1878-80 (aquando criação das casas de correção) houve 1096 menores; 1891-95 com 3384 menores; em 1903-10 (final da Monarquia) com 3392 menores (MARTINS, 1997). A criminalidade dos rapazes com menos de 18 anos era 5 a 6 vezes superior ao das raparigas, em que os fatores hereditários eram preponderantes (alcoolismo, tuberculose, sífilis, psicopatias, neuroses), individuais (debilidades físico-mentais, instabilidade, astenia, atraso mental ou pedagógico, epilepsia/histeria, doenças mentais, patologia) e mesógenos (má educação familiar ou falta dela, más companhias, ambiente envolvente) (CORRÊA, 1915). Os estudos científicos (jurídico-sociais, criminológicos, médicos, pedagógicos) alertavam para necessidade de prevenir essas situações da infância, numa luta contra os flagelos sociais, através de uma profilaxia social de correção e assistência (FERREIRA-DEUSDADO, 1890). A imagem social das crianças, nos bairros citadinos ou nas ruas era referida na imprensa com colunas apelativas para a opinião pública, com referência a prisões ou detenções, vadiagem, infrações e mendicidade. Só em novecentos essa problemática da menoridade delinquente começou a interessar os estudiosos no âmbito jurídico-social e médicopedagógica e os políticos e os filantropos, desenvolvendo-se medidas e estruturas de combate à criminalidade infantojuvenil e aplicação de modelos de intervenção.

Em termos economicistas, emerge com força nessa época o sistema correcionalista (prisional, júridico), como um sistema produtivo e de salvaguarda da coesão social, pois a sua base argumentativa centralizava-se na importância da reclusão, internação, regeneração moral e pelo trabalho. Assim, o Estado assegura com medidas (repressivas) esse período de internamento protetor, assistencial e educativo até que o internado se forme como um cidadão útil e, para tal, a internação em estabelecimentos 
(asilos, casas de correção, colónias correcionais), era o melhor dispositivo proteção. Ora esses menores internados passavam a sua infância estigmatizados em reclusão não tendo vivido uma infância desejada e normal, mas submetida a uma disciplina rigida e, assim, se reeducavam e se corrigiem, tal como a sociedade exigia. É um facto que em termos jurídicos a criminologia estava impregnada de positivismo (CORRÊA, 1914), influenciando o processo júridico-social de proteção, na confluência de propostas jurídicas e médicopedagógicas. Ou seja, a aplicação do método das ciências naturais aplicado ao social. O correcionalismo e os princípios repressivos do direito penal de oitocentos abordaram o problema da delinquência, mas não analisaram os condicionalismos físico-mentais, pedagógicos e socioeconómicos do sujeito (menor), pois ele era julgado pelo delito cometido e condições exógenas que o preverteram (FERREIRA-DEUSDADO, 1890). Só mais tarde se teve em conta a conceção e origem da delinquência com a ponderação dos fatores hereditátios (endógenos e a ordem social para a intervenção preventiva.

\section{Menor infrator: da via infame da marginalização à proteção no início de novecentos}

Os vadios e delinquentes menores apanhados pela polícia e julgados em tribunal sofriam vários tipos de condenações. Em alguns casos, a pena de prisão era emitida, sendo postos à disposição do Governo, para lhes dar trabalho. A pena de prisão podia ir de 3 dias a um máximo de 3 anos de prisão. Uma vez detidos e condenados seguiam para as casas de correção na época, Colónia Agrícola e Correcional Vila Fernando/Elvas (1880 e abriu em 1889), Real Oficina de S. José no Porto (1880) e estabelecimentos de beneficência, que proliferam desde o século XIX. Os que eram colocados em obras públicas iam para os distritos administrativos, onde faltasse mão-de-obra. Para a amior parte da 'Outra Infância' a rua era a aprendizagem do crime e nem os estabelecimentos prisionais o regeneravam, pois neles ainda incrementavam a sua maldade e criminalidade. O Padre António de Oliveira (1918, p. 59) ao chegar em 1898 à Casa de Detenção e Correção de Lisboa (às Mónicas), como capelão (e depois subdiretor) considerava essa instituição um "estábulo de gado humano", um lugar detenção de "bestas" ali despojadas, misturando-se crianças abandonadas/mendigas com as vadias, delinquentes e criminosas, ou seja, uma "monstruosa escola" de vícios e crimes. Esse ambiente que desde a sua fundação em 1871 manteve-se sempre degradante necessitava de uma transformação regulamentar e aquele padre consegui-o ao criar um novo Regulamento, 
em 1903, de acorde com os propósitos (médico)pedagógicos e reeducativos da época (MARTINS, 2012). Só mais tarde com a promulgação da LPI (PORTUGAL, 1911), se substituiu as casas de correção por escolas de reforma, implementando-se com maior eficácia as medidas jurídico-sociais e médico-pedagógicas de proteção.

Ao nível jurídico a idade do menor era o fator fulcral da sua responsabilidade criminal, correlacionada com a sua capacidade de discernimento no ato imputado. Os menores dividiam-se em dois grupos: os com idade entre os 10 e os 14 anos, com discernimento; os com idade entre os 14 e os 18 ou 21 anos suscetíveis de serem culpabilizados e sujeitos a penas, mas atenuadas pela menoridade. Processual e juridicamente havia diferenças com os adultos, contudo, o tribunal atuava preventivamente. Apesar destas medidas insípidas começou a gerar-se um movimento em prol da infância, distinguindo entre menores com ou sem discernimento e, por isso, rejeitava-se o regime repressivo e propunha-se um regime educativo em que se pudesse analisar em profundidade o menor tendo em conta o seu "[...] caso, sem preocupações de responsabilidade ou irresponsabilidade" (BELEZA DOS SANTOS, 1926, p. 45).

É bom lembrar que, paralelamente a esse movimento de defesa da criança, realizaram-se vários congressos internacionais abordando essa problemática sugerindo diversas medidas fragmentárias em alguns países, até se decretar a organização de Tribunais de Infância (1899, em Chicago), com a missão tutelar e não reprimir. Estas iniciativas difundiram-se na Europa (Inglaterra, Alemanha), de tal modo, que Portugal se antecipou à Bélgica, França, Itália e Espanha, na criação das Tutorias da Infância, promulgadas pela LPI $\left(\right.$ art. $^{\circ} 2^{\circ}$ ) (PORTUGAL, 1911). Inicia-se, assim, um novo tipo de direito - direito tutelar de menores, que constituía um direito preventivo, protetor, tutelar e educativo e, principalmente subjetivo, em que as medidas se ajustavam caso a caso. A Tutoria, como tribunal coletivo especial, tinha anexado o Refúgio e a coadjuvá-la a Federação Nacional dos Amigos e Defensores das Crianças, de modo a acolher, defender e proteger os menores desamparados, abandonados, delinquentes e em perigo moral, tendo como divisa a 'educação e trabalho' (ROCHA; FERREIRA, 1994).

Em matéria de legislação tutelar de menores Portugal conseguiu estar a par dos países mais avançados nas primeiras décadas do Século XX, porém as realizações de aplicação prática, a falta de meios económicos, de material e de recursos humanos, não acompanhava a produção teórica e legislativa. Contudo, os estabelecimentos destinados 
à regeneração dos menores eram em número insuficientes, superavam a lotação prevista, défice nas condições de funcionamento, etc. (CASTRO, 1913; VASCONCELOS, 1913). De facto, esta consagração tutelar, previdente e proveniente do Estado, em relação aquela infância, que por insuficiência de idade e vivendo em ambientes e situações de risco pessoal e social eram colocados sob a proteção pública, o que na prática inibia os poderes dos pais ou tutores, em relação à guarda, educação e correção desses menores de 12 anos, segundo o art. $^{\circ} 24^{\circ}$ da LPI (PORTUGAL, 1911). Esta intervenção jurídico-social, assistencial e educativa, colidia com o funcionamento autónomo da estrutura familiar, transferindo para o Estado essa responsabilidade, pela incapacidade ou inibição dos pais (LIMA, 1913). Em termos de punibilidade, os menores delinquentes agrupavam-se entre os que tinham de 9 a 12-13 anos e os com mais de 14 e menos de 16 anos. A diferença entre estes escalões estava na duração da pena de detenção, utilizada como último recurso para situações mais graves, que nos menores de 13-14 aos 16 anos podia ir até 5 anos com internamento numa casa de correção, enquanto os mais novos não ultrapassavam os 60 dias nos 'Refúgios' anexos às Tutorias Centrais (Lisboa, Porto e Coimbra), podendo ser internados em 'escolas de reforma' (Lisboa, Porto), entre 1911-19, passando depois a reformatórios até 1962 (reforma da organização tutelar de menores).

Na verdade, as causas de criminalidade infantil foram muito discutidas, com muitas explicações diferenciadas, segundo o enfoque teórico de análise (CASTRO, 1912), mas que convergiam para que: a educação viciada e a responsabilidade familiar; as seduções e promiscuidades do meio constituem a escola do vício e do crime; facilidade dos menores retirar proveitos do crime ou delitos (CORRÊA, 1915); instigação ao crime pelos adultos; más companhias ou camaradagens; anomalias individuais e algumas taras hereditárias. Como forma de prevenção a criminalidade infantojuvenil proibiu-se aos menores de 16 anos frequentarem casas de jogos, de passe ou de toleradas, tavernas, clubes, espetáculos de teatro ou cinema, etc. que pudessem desmoralizar ou ferir o seu pudor.

Em relação à detenção dos menores nas Tutorias da Infância a média de idade rondava os 12-13 anos de idade (MARTINS, 1997), muito desses comportamentos delitivos eram devidos às crises de adolescência e ao ambiente familiar que os levava a fugir de casa (maus-tratos, exploração, abandono, desamparo), da aprendizagem na oficina (sovas dos mestres, sem remuneração), na fábrica (chefes austeros, regime opressivo de horário, sem segurança laboral) e/ou da escola (inadaptação, insucesso). Em termos de 
uma cartografia espacial as distâncias percorridas por esses menores vadios/delinquentes eram curtas, sendo a cidade o polo de atracão das suas infrações (OLIVEIRA, 1929), apesar de alguns acompanharem os pais/família para a cidade, na procurava de emprego, uma vida melhor ou de sobrevivência, mas com recurso à mendicidade e beneficência (albergues, irmandades, asilos, recolhimentos) (SANTOS, 2002). O ambiente urbano citadino fomentava, devido aos desajustamentos socioeconómicos, o aparecimento da criança pobre, mendiga, indigente e vadia, que sem meios económicos necessários de subsistência e sem ajuda social, rapidamente passa para a 'outra margem', a da ilegalidade, onde circulavam as franjas de criminosos, operários desafortunados, dedicados à vagabundagem e roubo (SANTOS, 1996). Daí que a vadiagem e vagabundagem constituíam um fenómeno (sub)urbano de tendência para delinquência.

Se recorremos aos anuários estatísticos nas Tutorias Centrais de Infância (Lisboa, Porto e Coimbra) e nas Comarcãs, em 1927 (finais da 1. ${ }^{a}$ República), houve 783 menores processados, tendo havido uma grande intervenção durante este período republicano, com a legislação de 1911 e 1925. As variáveis e indicadores (dados quantitativos) desses menores julgados nesse ano foram os seguintes (MARTINS, 1997):

(i.) -Idade e sexo dos delinquentes, indisciplinados e em perigo moral: menores entre 13 a 15 anos (34,1\%), menores de mais de 15 anos (27,7\%) e entre 11 a 13 anos de idade (19,9\%); a maior parte tinha por naturalidade Lisboa, Porto, Coimbra, Aveiro, Viseu, Santarém, etc.;

(ii.) -Instrução (analfabetos, sabiam ler/escrever e instrução desconhecida) desses menores: com filiação legítima e analfabetos $37,7 \%$ e sabiam ler/escrever $31,4 \%$; nos menores ilegítimos havia $14,7 \%$ de analfabetos e $9,5 \%$ que sabiam ler/escrever. No total houve 52,4\% de menores analfabetos, 40,9\%, sabiam ler/escrever e 6,7\%. desconhecida.

(iii.) -Filiação (legitima, ilegítima e incógnita ou desconhecida) nos menores processados houve 559 legítimos (71,4\%), 199 ilegítimos (25,4\%) e 25 de filiação desconhecida $(3,2 \%)$.

(iv.) -Antecedentes mórbidos (alcoolismo, tuberculose, sífilis, prostituição, etc.). Não existiam dados estatísticos referentes aos "fatores hereditários" ou "antecedentes mórbidos 'neste ano, pois as referências estatísticas não eram de forma contínua, destacando que nesta época o papel dos postos antropométricos ou antropológicos foi importante, sobretudo o do Porto. A maior percentagem de menores detidos não possuía 
antecedentes mórbidos, principalmente alcoolismo familiar, tuberculose, sífilis, a associação entre o 'alcoolismo, tuberculose e sífilis' e, ainda, a prática da prostituição, delinquência reincidente, loucura, etc., mas rondava entre os $6 \%$ a $8 \%$ de antecedentes de alcoolismo e $4 \%$ de tuberculose relativos aos pais (MARTINS, 2012).

(v.) -Profissão. Os menores processados como delinquentes, indisciplinados e em perigo moral nas Tutorias da Infância apresentavam na sua maioria a situação de 'sem profissão ou profissão ignorada', seguindo-se, 'escolares que abandonaram a escola', serviçais, profissões domésticas, trabalhadores rurais, empregados comerciais, vendedores ambulantes, etc., maioritariamente menores do sexo masculino.

(vi.) -Decisões ou medidas judiciais: 'sem decisão/pendentes' (33,8\%); internados em escolas de reforma (13,8\%); colocados em liberdade vigiada (13,4\%); absolvidos (11,5\%); internados em estabelecimentos de assistência (6,3\%); internados nos refúgios e colónias agrícolas (6,6\%); repreendidos (5,2\%), etc.

Ao serem criados os reformatórios, em 1919, destinados aos menores que ainda não estavam 'gravemente pervertidos', podendo ser corrigidos com uma ação reformadora pelo trabalho oficinal, pela educação moral, instrução elementar e meios disciplinares adequados. As colónias correcionais (Vila Fernando, Izeda) serviam para os menores 'incorrigíveis' com certo grau de perversão, mas suscetíveis de regeneração pelo trabalho agrícola e aprendizagem de um ofício, educação moral e rigorosa disciplina (Art. ${ }^{\circ}$ $107^{\circ}$ e $108^{\circ}$ do Decreto n. ${ }^{\circ} 10767$, de 15/maio/1925). Este diploma jurídico reflete o principio do direito de menores, ou seja, a noção de que para definir o menor como delinquente interessava menos a prova do crime/delito do que a averiguação das condições de ordem subjetiva. Defendia-se a intervenção de medidas preventivas do crime, já que essa ação reduziria o número de casos carentes de internamento. As teorias reeducativas da época apontavam para a observação e regeneração dos menores delinquentes aproximando-os às condições normais de vida, sadia e honesta, de modo a constituir a vida de internato numa prova de adaptação e de boa conduta perante as normas jurídicas e da moral social.

\section{CONSIDERAÇÕES FINAIS}

Numa forma metafórica e de um jogo de espelhos em temos das conceções atribuídas à infância, o contrário de criança em perigo (moral) era a própria criança em si, 
pois a aceção de perigo moral (em risco) converte-se num perigo de marginalização, desvio social ou delinquência. A infância que circundava pelas ruas, vagabundando ou infringindo delitos, estava imersa num ambiente promíscuo, imoral ou sujeito a várias influência que em nada abonava o seu normal desenvolvimento educativo e social. Salvando as devidas distâncias as crianças de oitocentos e novecentos sofreram o racismo de classe social, pois estavam à margem das outras ditas normais, já que a criança perigosa, errante e infratora era conotada com as classes operárias, trabalhadoras, pobres ou em miséria. Estas e outras conceções percorreram parte desses centúrios, onde vários quadrantes de científicos, de políticos, de filantrópicos (e maçonaria) e escritores/intelectuais apelavam para a salvação dessas crianças e exigiram dispositivos de proteção e assistência. Um exemplo, foi o decreto de 1888 que, ao regulamentar os serviços de expostos e da infancia desvalida, incumbiu as Câmaras Municipais dessa ação.

Historicamente houve construções (sociais, culturais) sobre a infância, que numa perspetiva diacrónica acompanhou uma evolução temporal (fatual, sucessivo) com princípios de proteção e correção, que foram substituindo o sistema punitivo/repressivo para um tutelar e reeducativo, assim como, criação de dispositivos assistenciais para 'Outra Infância'. Sincronicamente a literatura documental, incluindo a imprensa, os debates públicos, os discursos científicos e político-ideológicos preocuparam-se pela conceção e representação da infância infratora, em perigo moral ou delinquente, que constituía um perigo social e, daí a criação de estabelecimentos educativos por parte do Estado. Nessa simbiose de triangulação diacrónica e sincrónica em termos de políticas sociais e educativas, houve uma preponderância do positivismo (antropológico, criminal, jurídico-social) e das ciências da criança, que promoveram na prática princípios (inovadores) de proteção e prevenção à infância portuguesa.

Os discursos sobre a conceção e a questão social da criança/infância implicaram uma certa 'infantilização' da classe social a que pertenciam essas infâncias. É evidente que os mecanismos discursivos vigentes (reformas sociais) responderam com estratégias de controlo social, orientados à conformação de dispositivos específicos, por exemplo: a correção de menores delinquentes e infratores (repressão e disciplina); assistência educativa à infância desvalida - vadia (regeneração e moralização); assistência aos expostos (pobres, órfãos, mendigos); doutrinamento instrutivo da criança na escola (classes sociais). Ora todos estes mecanismos estruturam-se numa cartografia conceptual 
que representa a metáfora da família -modelo social e núcleo semântico, sustentáculo do sistema discursivo, dos seus atores e relações e, inclusive das oposições existentes: Estado (classe governante - elitista) -sociedade (classes sociais dominantes -burguesia) e Igreja, perante a família e as crianças, as quais se lhes deu a figura do Juiz de menores (e curadores), na ação de um bom pai de família. Todo estes dispositivos se fortaleceram no séc. XX, como um sistema de, com intuito de afastar as crianças do perigo moral, da vadiagem e da delinquência, modificando estabelecimentos e serviços de coerção e disciplina, de internação para semi-internato e semi-liberdade, em que o setor privado filantrópico e religioso foi um auxiliar do Estado paternalista e tutor, ao configurar uma cultura de jurisdição e legitimação dos problemas sociais (CATROGA, 1977). Em relação à profilaxia e terapêutica social dos menores delinquentes, indisciplinados e em perigo moral a legislação promulgada em termos de proteção, prevenção e promoção formativa evoluiu desde 1911 e ao longo do século (até 1977 - direito tutelar de menores e depois direito educativo), mas continuou por colmatar certas situações das crianças em risco.

Por conseguinte, a ideia de que todas as crianças têm as mesmas oportunidades de vida e de uma infância normalizada, nem sempre foi assim. Outras infâncias, muitas delas em situação social/familiar de pobreza/miséria ou condições de abandono e desamparo mereceram dos reformadores sociais medidas assistenciais ou de internação asilar educativa ou, então, caiam nas malhas da polícia e justiça por práticas de vadiagem (infância desvalida), em perigo moral e em delinquência sofrendo as deliberações dos códigos penais de oitocentos e, depois, a LPI de 1911, de 1925 e 1962. Todas essas infâncias, diferenciadas da normalizada e socializada com os padrões sociais, tiveram comportamentos antissociais, desviação ou marginalização social, convertendo-se numa questão social para a governação e para os discursos politico-ideológico da época e, ainda objeto de estudo de várias ciências presionando as autoridades para medidas proteção.

\section{REFERÊNCIAS}

BARBAS, A. Ação moral da tutoria. A Tutoria, Lisboa, v. 1, n. 1, out. 1912. p. 5-8.

BELEZA DOS SANTOS, J. Regime jurídico dos menores delinquentes em Portugal. Coimbra: Coimbra Editora, 1926. 
BORRÁS LLOP, J. Ma (dir.). Historia de la infancia en la España contemporánea 1834-1936. Madrid: Ministério de Asuntos Sociales, 1996.

CARRILLO, S.; ASTARITA, C.; VOGEL, H.; PETIT, J-G. et al. Disidentes, heterodoxos y marginados en la historia. Salamanca: Ediciones de la Univ. De Salamanca - Acta Salmanticense - Estudios Histórico \& Geográficos, 1998.

CASTRO, Pedro A.P. Causas da criminalidade infantil. A Tutoria, Lisboa, v. 1, n. 3, dez. 1912. p. 35-36.

CASTRO, Pedro A.P. Comissão de proteção a menores. A Tutoria, Lisboa, v. 1, n. 4, jan. 1913, p. 56-57.

CATROGA, F. A. A importância do positivismo na consolidação da ideologia republicana em Portugal. Coimbra: Pub., Faculdade de Letras/Univ. Coimbra, 1977.

CÓDIGO PENAL PORTUGUÊS. Decreto com força de Lei, de 10 de dezembro de 1852.

CÓDIGO PENAL PORTUGUÊS. Decreto de 16 de setembro (D. G.20/09), de 1886.

CORRÊA, A. A. Mendes. Os criminosos portugueses. Coimbra: F. França Amado, Ed., 1914.

CORRÊA, A. Augusto Mendes. Creanças delinquentes: subsídios para o estudo da criminologia infantil em Portugal. Coimbra: F. França Amado, Ed., 1915.

FERREIRA, $M^{a} M$. Salvar corpos, forjar a razão: contributo para uma análise crítica da criança e da infância como construção social em Portugal, 1880-1940. Lisboa: I.I.E., 2000

FERREIRA-DEUSDADO, M. A. Ideias sobre educação correcional. Lisboa: Editores Guillard Aillaud, 1890

FONSECA, J.A. F. Estudos médico-sociais: a luta contra a degenerescência. A Tutoria, Lisboa, v. 1, n. 7, abr. 1913. p. 101-104.

FOUCAULT, M. É preciso defender a sociedade. Lisboa: Livros do Brasil, 2006.

GENOVÊS, Vicente Garrido. Pedagogía de la delincuencia juvenil. Barcelona: Ceac, 1990

GOMES, António Luís. Ociosidade, vagabundagem e mendicidade. Estudo social e jurídico. Coimbra: Imprensa da Universidade Coimbra, 1892, p. 137-149.

LIMA, J.S. As novas leis da infância em Portugal. A Tutoria, n. 3, dez. 1913. p. 44-45.

LOPES, Alfredo Luíz. Estudo estatístico da criminalidade em Portugal nos anos de 1891 a 1895. Lisboa: Imprensa Nacional, 1897 
KING, M. Concepts of childhood: what we know and where we might go. Renaissance Quarterly, Chicago, v. 60, n. 2, 2007, p. 371-400.

MAGALHÃES, J. Presentação da infância. A Tutoria, Lisboa, v. 1, n. 2, nov. 1912. p. 20.

MARTINS, E. C. Proteção e reeducação dos menores abandonados, marginados e delinquentes em Portugal. Veritas, Porto Alegre, v. 42, n. 2, jun. 1997. 349-364.

MARTINS, E.C. Proteção social e (R) educação de menores: o padre António d' Oliveira (1867-1923). Lisboa: Cáritas Editora, 2012.

MINISTÉRIO DA JUSTIÇA E DOS CULTOS. Serviços jurisdicionais e tutelares de menores: tutoria central de infância de Lisboa. Lisboa: Imprensa Lucas Comp. ${ }^{a}, 1931$.

OLIVEIRA, (Pe.) António de. Criminalidade, educação. Lisboa: Livraria Aillaud e Bertrand, 1918.

OLIVEIRA, (Pe.) António de. Salvemos a raça. Lisboa: Edição do Autor, 1923.

OLIVEIRA, Augusto de. Proteção moral e jurídica à infância. Lisboa: Tip. Do Reformatório Central de Lisboa ‘Pe. António de Oliveira', 1929.

PERROT, M. (ed.). L'Impossiblee prison: recherches sur le système pénitentiaire au XIXe siècle: débat avec Michel Foucault. Paris: Éditions du Seuil, 1980.

PINTO, $M^{a}$ de Fátima. Os indigentes: entre a assistência e a repressão - a outra Lisboa no 1. ${ }^{\circ}$ Terço de século. Lisboa: Livros Horizonte, 1999.

PORTUGAL. Diários do governo: legislação. Lisboa: Imprensa Nacional, 1880-1962.

PORTUGAL. LPI -Lei de proteção à infância, de 27 de maio/1911 (D:G. nº 317, 14/junho). Lisboa, 1911.

SANTOS, $M^{a}$ José Moutinho. Os jovens delinquentes nas prisões do porto oitocentista. Revista de Ciências Históricas, 1996, p. 189-204.

SANTOS, $M^{a}$ José Moutinho. A sombra e a luz: as prisões do liberalismo. Porto: Edições Afrontamento, 1999.

SANTOS, $M^{a}$ José Moutinho. Crianças e jovens em risco nos séculos XVIII e XIX. O caso português no contexto europeu. Revista de História da Sociedade e da Cultura, Coimbra, n. 2, 2002, p.155-184.

ROCHA, Cristina; FERREIRA, $M^{a}$ Manuela. Alguns contributos para a compreensão da construção médico-social da infância em Portugal (1820-1950). Educação, Sociedade \& Culturas, Porto - Edições Afrontamento, n. 2, 1994, p. 59-90. 
ROTHMAN, D.J. The discovery of the asylum: social order and disorder in the new republic. Boston: Little, Brown and Company, 1971.

TOMÉ, M.R.A. Cidadania infantil na primeira república e a tutoria da infância. A criação da tutoria de coimbra e o refúgio anexo. Revista de História da Sociedade e da Cultura, Coimbra, v. 11, n. 10, 2010. p. 481-500.

VASCONCELOS, Ernesto Leite de. O problema da criminalidade infantil. A Tutoria, n. 6, mar. 1913. p. 88-89.

XAVIER, Ângela B. Imagem de pobres, pobreza e assistência entre os séculos XV e XX. In: PAIVA, J. Pedro (coord.), Portugaliae monumenta misericordiarum. Lisboa: União das Misericórdias Portuguesas, 2017, p. 15-41.

Recebido em: 27/04/2020

Parecer em: 22/06/2020

Aprovado em: 11/11/2020 